\title{
EXERCÍCIO DE FORÇA ASSOCIADO A ÓLEO DE PEIXE REDUZEM MASSA TUMORAL E CAQUEXIA EM RATOS
}

\author{
RESISTANCE EXERCISE AND FISH OIL REDUCE TUMOR MASS AND CACHEXIA IN RATS
}

EJERCICIO DE FUERZA ASOCIADO A ACEITE DE PESCADO REDUCE LA MASA TUMORAL

Y LA CAQUEXIA EN RATAS

Renata Teixeira Mamus Gomes (Educadora Física)

Marcelo Kryczyk² (Educador Físico) Luciele Minuzzi² (Educadora Física) Gina Borghetti (Fisioterapeuta) Julia Aikawa² (Bióloga)

Danielle Cristina Tonello Pequito² (Farmacêutica e Bioquímica)

Isabela Coelho ${ }^{2}$ (Nutricionista)

Luiz Cláudio Fernandes'

(Biólogo)

1. Departamento de Educação Física, Setor de Ciências Biológicas, Universidade Federal do Paraná, Curitiba, PR, Brasil.

2. Departamento de Fisiologia, Setor de Ciências Biológicas, Universidade Federal do Paraná, Curitiba-PR, Brasil,

\section{Correspondência:}

Av. Senador Souza Naves, 635, apt. 212, Alto da Rua XV, 80045-190,

Curitiba, PR, Brasil.

rtmamus@yahoo.com.br

\section{RESUMO}

Objetivo: Investigar o efeito do treinamento de salto associado à suplementação com óleo de peixe $(1 \mathrm{~g} / \mathrm{kg}$ peso corporal/dia) em ratos portadores do tumor de Walker 256, sobre parâmetros bioquímicos de caquexia e crescimento tumoral. Métodos: Oitenta Ratos foram divididos em sedentário sem ou com tumor (S ou SW), exercitado (EX ou EXW), suplementado com óleo de peixe (SO ou SWO) e suplementado e exercitado (EXO ou EXWO). Sessões de treinamento de salto consistiram de 10 séries com duração de 30 segundos e intervalo de 1 minuto entre cada série. Após seis semanas de treinamento, células do tumor de Walker 256 foram inoculadas e após 15 dias os animais foram mortos. Resultados: O peso médio do tumor no grupo SW foi de 25,32 g, p<0,05 vs. ao dos SWO, EXW e EXWO ( 11 g). O grupo SW apresentou hipoglicemia, hiperlactatemia, hipertriacilglicerolemia e perda de peso $(-7,52 \pm 3,19 \mathrm{~g})$, caracterizando estado caquético. Suplementação com óleo de peixe (SWO), exercício (EXW) e associação de ambos (EXWO) impediram a instalação da caquexia ( $p<0,05$ vs. SW). No grupo SWO, EXW e suas associações (EXWO) promoveram ganho de peso ( $p<0,05$ vs. SW), mas inferior ao da suplementação isolada ( $p<0,05$ vs. SWO). A proliferação celular in vitro das células tumorais foi menor no grupo SWO ( $p<0,05$ vs. SW) e o exercício reduziu ainda mais ( $p<0,05$ vs. SW e SWO), não havendo incremento quando se associaram ambas as terapias. Lipoperoxidação $(p<0,05)$ foi maior nos SWO, EXW, EXWO vs. S. A expressão de Bcl-2 foi menor também nestes grupos vs. SW. Conclusões: $\mathrm{O}$ treinamento de força e a suplementação com óleo de peixe foram eficazes em evitar a caquexia e induzir a redução do crescimento tumoral, da proliferação tumoral e expressão de BCl-2, mas a associação de ambos não promoveu efeito aditivo.

Palavras-chave: exercício, câncer, caquexia, óleo de peixe.

\section{ABSTRACT}

Objective: To investigate the effect of jump training associated with fish oil (FO) supplementation (1 g/Kg bodyweight/day) on biochemical parameters of cachexia and tumor growth in Walker 256 tumor-bearing rats. Methods: Eighty rats were divided into sedentary non- and tumor-bearing (S and SW), exercised (EX and EXW), FO supplemented (SO and SWO), and both supplemented and exercised (EXW and EXWO). Jump training sessions consisted of 10 series of 30 seconds each, followed by 1 minute of rest. After six weeks of jump training, ascitic cells from Walker 256 tumor bearing-rat were inoculated, and after 15 days, all the animals were sacrificed. Results: The tumor mass in the SW group was $25.32 \mathrm{~g}, p<0.05$ vs the SWO, EXW and EXWO groups ( $11 \mathrm{~g}$ ). The SW group presented hypoglycemia, hyperlactacidemia and hypertriacylglycerolemia and a reduction in body weight $(-7.52 \pm 3.19 \mathrm{~g})$, characterizing a state of cachexia. Supplementation with fish oil (SWO), exercise (EXW) and both (EXWO) prevented the onset of cachexia and promoted weight gain ( $p<0.05 \mathrm{vs} S W$ ), but less than that of the supplementation alone ( $p<0.05 \mathrm{vs} S W O$ ). In vitro cell proliferation of the tumor cells was lower in the SWO group ( $p<0.05 \mathrm{vS} S W$ ) and exercise reduced still further $(p<0.05$ vs. SW and SWO), with no increase when both therapies were applied together. Lipoperoxidation $(p<0.05)$ was higher in the SWO, EXW, EXWO groups vs. S. BCl-2 expression was also lower in these groups vs. SW. Conclusions: Jump training and fish oil supplementation alone were able to effectively prevent cachexia and reduce tumor growth, tumor cell proliferation, and $\mathrm{BCl}-2$ expression, but the combination of both did not promote any additive effect.

Keywords: exercise, cancer, cachexia, fish oil.

\section{RESUMEN}

Objetivo: Investigar el efecto del entrenamiento de salto asociado a suplementación con aceite de pescado (1 g/kg peso corporal/día) en ratas portadoras del tumor de Walker 256 de acuerdo con los parámetros bioquímicos de la caquexia y el crecimiento tumoral. Métodos: Ochenta ratas fueron divididas en sedentarias sin y con tumor (S o SW), ejercitadas (EX O EXW), suplementadas con aceite de pescado (SO o SWO) y ejercitadas y suplementadas de forma simultánea (EXO o EXWO). Las sesiones de entrenamiento de salto consistieron en 10 series de 30 segundos cada una seguidas por 1 minuto de descanso entre cada serie. Después de seis semanas de entrenamiento, las células del tumor de Walker 256 se inocularon en las ratas y 15 días después todos los animales fueron sacrificados. Resultados: El peso medio del tumor en el grupo SW fue de 25,32 g $(p<0,05)$ con respecto a los grupos SWO, EXW y EXWO $(\sim 11 \mathrm{~g})$. El 
grupo SW presento hipoglucemia, hiperlactatemia y hipertriacilglicerolemia y reducción de peso corporal (-7,52 \pm 3,19 g), lo que caracteriza el estado caquéctico. La suplementación con aceite de pescado (SWO), el ejercicio (EXW)

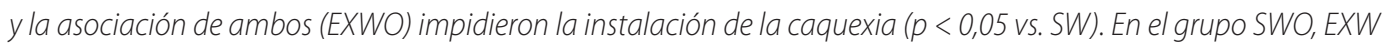
e sus asociaciones (EXWO) promovieron aumento de peso ( $p<0,05 \mathrm{vs}$. SW), pero inferior al de la suplementación aislada ( $p<0,05$ vs. SWO). La proliferación in vitro de las células tumorales fue menor en el grupo SWO ( $p<0,05$ $v s$. SW) y el ejercicio la redujo todavía más ( $p<0,05$ vs. SW e SWO), no habiendo incremento cuando se asociaran ambas las terapias. La lipoperoxidación fue mayor en los grupos SWO, EXW, EXWO con respecto al grupo $S$ ( $p<$ 0,05). La expresión de BCl-2 en estos grupos también fue menor que en SW. Conclusiones: El entrenamiento de fuerza y la suplementación con aceite de pescado fueron eficaces en como prevención de la caquexia y en la reducción del crecimiento del tumor, de su proliferación y de la expresión de BCl-2, pero la asociación de ambos no causó un efecto aditivo.

Palabras clave: ejercicio, cáncer, caquexia, óleo aceite de pescado.

\section{INTRODUÇÃO}

Alguns pacientes com câncer podem desenvolver a síndrome metabólica complexa denominada caquexia, caracterizada por progressiva perda de peso, anorexia, astenia, anemia, náusea crônica, imunossupressão, depressão, diminuição da capacidade aeróbica, fadiga, diminuição da força muscular e flexibilidade, atrofia muscular e acentuada perda de massa muscular ${ }^{5}$. A perda de peso é uma das características mais evidentes e está essencialmente relacionada com a diminuição da massa muscular, que em estágio avançado pode comprometer funções cardíacas e respiratórias ${ }^{27}$. Desta forma, intervenções que preservem a massa muscular têm implicações clínicas importantes em relação à qualidade de vida do paciente com câncer.

Dentre as diversas alternativas terapêuticas para o tratamento do câncer, o treinamento de força induz a efeitos benéficos, pois minimiza a perda progressiva de massa muscular ${ }^{1}$. Este tipo de treinamento eleva as taxas de síntese proteica no tecido muscular esquelético e induz a ganhos significativos de força e massa magra nos indivíduos que o praticam.

O óleo de peixe, rico em ácidos graxos poli-insaturados n-3 (AGPIs $\mathrm{n}$-3), tem sido demonstrado capaz de reduzir o crescimento tumoral e a caquexia ${ }^{18,23}$. Os mecanismos celulares e moleculares responsáveis por estes efeitos, entretanto, ainda não são completamente conhecidos.

Estudos sobre a associação de exercício de força e suplementação com óleo peixe sobre crescimento tumoral e caquexia são escassos, bem como a abordagem dos possíveis mecanismos que levam à redução do crescimento tumoral. Aqui, investigamos o efeito do treinamento de salto associado à suplementação com óleo de peixe sobre os parâmetros de caquexia e crescimento tumoral em ratos e quais mecanismos celulares participam deste processo.

\section{MÉTODOS}

Para a realização deste estudo foram utilizados ratos albinos adultos (70 dias) da linhagem Wistar (Rattus norvegicus), obtidos do Biotério do Setor de Ciências Biológicas da Universidade Federal do Paraná. Todos os procedimentos foram aprovados pelo Comitê de Ética em Experimentação Animal (CEEA) do Setor de Ciências Biológicas (SCB) da Universidade Federal do Paraná, PR, Brasil (UFPR), certificado no 445.

Os animais foram mantidos em ciclo circadiano (12/12 horas), com temperatura controlada de $23 \pm 1{ }^{\circ} \mathrm{C}$, com livre acesso a água e alimento (Nuvilab-Nuvital). Foram divididos aleatoriamente em oito grupos: Sedentário sem suplementação (S), Sedentário suplementado com óleo de peixe (SO), Sedentário portador de tumor (SW), Sedentário portador de tumor suplementado com óleo de peixe (SWO), Exercitado sem suplementação (EX), Exercitado suplementado com óleo de peixe
(EXO), Exercitado portador de tumor (EXW), Exercitado portador de tumor e suplementado com óleo de peixe (EXWO). O exercício de força foi realizado por sessões de treinamento de salto que consistiram de 10 séries com duração de 30 segundos e intervalo de 1 minuto entre cada série. Após seis semanas de treinamento, $1 \mathrm{ml}$ de suspensão contendo $3 \times 10^{7}$ células do tumor ascítico de Walker 256 foi inoculado subcutaneamente no flanco direito dos animais identificados como portadores do tumor. Após 15 dias da inoculação do tumor, coincidindo com a oitava semana de treinamento, os animais foram ortotanasiados. Todos os grupos foram mortos 48 horas após a última sessão de exercício, eliminando os efeitos agudos do exercício sobre parâmetros metabólicos. O peso corporal foi medido regularmente durante o período experimental. O tumor foi removido, pesado e amostra retirada para estudo. O sangue foi recolhido e o soro separado para medir as concentrações de glicose, lactato e triacilglicerol.

A concentração de glicose foi quantificada por método colorimétrico utilizando-se sistema comercial Glicose E enzimática (Labtest) em espectrofotômetro (Ultrospec 2000, Pharmacia Biotech) a 505 nm. A concentração de triacilglicerol (TAG) foi determinada pelo método enzimático colorimétrico conforme o sistema comercial BIOTÉNICA e a leitura da absorbância feita a 540nm. A concentração de lactato foi determinada enzimaticamente. Inicialmente foi feita a desproteinização do soro, pela adição de $50 \mu \mathrm{L}$ de ácido tricloroacético (TCA) a 25\% a $0,5 \mathrm{~mL}$ da amostra e a mistura foi agitada em vortex e centrifugada por 1 minuto a 13.000 rpm. Em seguida, foi coletado $200 \mu \mathrm{L}$ do sobrenadante e adicionou-se $4 \mu \mathrm{L}$ de indicador universal para permitir a visualização da neutralização do soro, pela adição de KOH/TRIS (0,5 M/2 M), sinalizada pela coloração verde, indicando pH 7,0. Deste volume neutralizado pipetou-se $100 \mu \mathrm{L}$ em tubos de ensaio contendo $1 \mathrm{~mL}$ do tampão do ensaio e, após 45 minutos, foi feita leitura em espectrofotômetro a $340 \mathrm{~nm}$.

Amostras da massa tumoral foram colocadas em placa de Petry contendo salina gelada $(0,9 \%)$ e cortadas com tesoura para permitir o isolamento as células do tumor de Walker-256, as quais foram na sequência cultivadas em meio de cultura RPMI-1640 enriquecido com 10\% de soro fetal bovino, na presença de antibióticos (penicilina $10.000 \mathrm{U}$ e estreptomicina $10 \mathrm{mg} / \mathrm{L}$ ). As células foram semeadas em placas de 96 poços, $1 \times 10^{5}$ células por poço, a $37^{\circ} \mathrm{C}$ em atmosfera de $95 \%$ ar e $5 \%$ de $\mathrm{CO}_{2}$. Aos poços foram adicionados $20 \mu \mathrm{L}$ de $\left({ }^{14} \mathrm{C}\right)$ -timidina $(0,02 \mu \mathrm{Ci} /$ poço) e as células foram cultivadas por 48 horas. Após este período, as células foram coletadas automaticamente em coletor múltiplo (Skatron Combi Multiple Cell Harvester, UK) em papéis filtro no 11731 (Skatron Combi, UK). Os discos de papéis contendo o radioisótopo incorporado ao DNA foram transferidos para tubos 
contendo $1 \mathrm{~mL}$ de líquido de cintilação e levados para contagem da radioatividade em contador Beckman LS 6000.

A peroxidação lipídica foi mensurada pelo método descrito por JIANG, WOOLLARD \& WOLFF'11. Neste método, os hidroperóxidos formados oxidam o ferro a íon férrico, o qual, por sua vez, se liga ao corante xilenol laranja. Duzentos gramas de amostra de tumor de Walker 256 foram homogeneizados em $1 \mathrm{~mL}$ de metanol e centrifugados a $5.000 \mathrm{~g}$ por 5 minutos a $4^{\circ} \mathrm{C}$. Para cada amostra, alíquotas de $90 \mu \mathrm{L}$ do sobrenadante foram pipetadas tubos de ensaio. Em metade destes tubos foram adicionados $10 \mu \mathrm{L}$ de solução metanólica de trifenilfosfina (TPP) a 10 mM, para redução seletiva de hidroperóxidos. Nas amostras contidas nos outros tubos foram pipetados 10 $\mu \mathrm{L}$ de metanol. Todos os tubos foram agitados e incubados em temperatura ambiente por 30 minutos. Terminada esta incubação, adicionou-se a cada tubo $900 \mu \mathrm{L}$ do reagente FOX2 (xilenol laranja a $100 \mu \mathrm{M}$, hidroxitolueno butilado a $400 \mathrm{mM}$, ácido sulfúrico a 25 mM e sulfato ferroso de amônia em metanol 90\%). Após agitação, incubou-se à temperatura ambiente por mais 30 minutos. A leitura da absorbância foi realizada em espectrofotômetro a 560 nm. Para a determinação da concentração de hidroperóxidos nas amostras, subtraiu-se o valor da absorbância das amostras tratadas com TPP do valor da absorbância das amostras sem TPP. O valor obtido foi, então, interpolado na curva padrão de peróxido de hidrogênio, a qual foi obtida com soluções padrão de peróxido de hidrogênio de diferentes concentrações (100.0, 50.0, 25.0, 12.5, 6.2, 3.1 e 1.6 $\mu \mathrm{M})$ submetidas aos mesmos procedimentos descritos acima para a mensuração de lipoperóxidos.

Determinação da expressão da proteína bcl-2: Esta proteína foi mensurada por Western Blotting. Amostras de 100mg do tecido tumoral foram fragmentadas mecanicamente com o auxílio de um homogeneizador (BOSCH ${ }^{\circledR}$ GGS27 25.000 rpm/min) em tampão de lise (Tris base 100mM, EDTA 10mM, SDS 1\%, Fluoreto de Sódio $100 \mathrm{mM}$, Pirofosfato de Sódio 10mM, Ortovanadato de Sódio 10mM) na proporção de 1:7, centrifugados durante 5 minutos a 18000 rpm (Eppendorf centrifugue ${ }^{\circledR} 5810$ R) e o sobrenadante coletado para a quantificação proteica, utilizando o método de Bradford ${ }^{3}$. Após quantificação proteica, todas as amostras foram diluídas a $3 \mu \mathrm{g} / \mu \mathrm{L}$. Em seguida, as amostras foram fervidas durante 5 min e submetidas a eletroforese SDS em gel de poliacrilamida (12\% de poliacrilamida), seguido por transferência eletroforética (BIORAD ${ }^{\circledR}$ Semi-dry transfer cell) para membrana de nitrocelulose (BIO-RAD ${ }^{\circledR}$ TRANSBLOT) durante aproximadamente 1 hora sob voltagem constante de $25 \mathrm{~V}$ $\left(5,5 \mathrm{~mA} / \mathrm{cm}^{2}\right)$, contendo tampão de Transferência Bjerrum e Schafer-Nielsen (48 mM Tris, 39 mM glicina, 10\% SDS e 20\% metanol) previamente resfriado a $4^{\circ} \mathrm{C}$. A membrana foi bloqueada por 1 hora à temperatura ambiente com tampão de bloqueio TBST ( $\mathrm{NaCl} 4 \mathrm{M}$, Tris HCl 1M, 0,05\% Tween 20) contendo 5\% de leite desnatado. Posteriormente, a membrana foi incubada com o anticorpo primário contra Bcl-2 (Santa Cruz ${ }^{\circledR}$ Biotechnology), diluído na proporção de 1:800. A membrana, após lavagens com TBST, foi incubada com anticorpo secundário conjugado diluído na proporção de 1:4.000 em tampão de bloqueio 3\% por 2 horas à temperatura ambiente. O controle interno foi feito com anti-total $\beta$-actina (1:500). Finalmente, as membranas foram submetidas à solução de quimioluminescência (Super Signal Sistemas Pierce). A membrana foi escaneada e analisada pelo software Image J.

Os dados estão expressos como média \pm Erro Padrão da Média (EPM) de cinco experimentos em triplicata e submetidos a análise de variância de duas vias com pós-teste de Bonferroni, tendo como fatores o exercício e a suplementação. O nível de significância adotado foi de 5\% ( $p<$ 0,05). O software estatístico empregado foi o GraphPad Prism ${ }^{\circledR}$ versão 5.0.

\section{RESULTADOS}

O peso do tumor (figura 1) no grupo sedentário portador de tumor (SW) foi de 25,32+4,37 g. A suplementação com óleo de peixe (SWO) reduziu a massa tumoral para 13,65 $\pm 2,92 \mathrm{~g}$ ( $p<0,05$ vs. SW). 0 exercício de salto (EXW) teve também efeito redutor da massa tumoral para 12,78 $\pm 2,25 \mathrm{~g}(\mathrm{p}<0,05 \mathrm{vs}$. SW). A associação do exercício de salto e suplementação com óleo de peixe (EXWO) reduziu a massa tumoral para 9,69 $\pm 1,59 \mathrm{~g}(\mathrm{p}<0,05 \mathrm{vs}$. SW), a qual não foi diferente quando comparada à dos grupos SWO, EXW e EXWO ( $p>0,05)$.

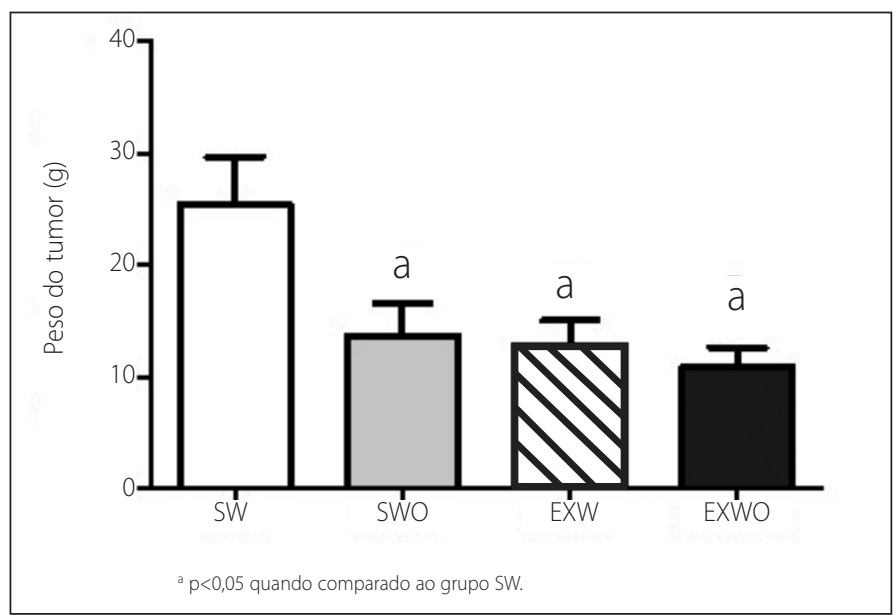

Figura 1. Peso dos tumores dos grupos Sedentário portador de tumor (SW), Sedentário portador de tumor suplementado com óleo de peixe (SWO), Exercitado portador de tumor (EXW) e Exercitado portador de tumor suplementado com óleo de peixe (EXWO). Os dados representam a média \pm EPM de 5 experimentos em triplicata

A presença do tumor levou o grupo SW a hipoglicemia $(57,70 \pm 0,91$ $\mathrm{mg} / \mathrm{dl})$, hiperlactatemia $(1,49 \pm 0,01 \mathrm{mmol} / \mathrm{L})$ e hipertriacilglicerolemia $(183 \pm 21,19 \mathrm{mg} / \mathrm{dl})$ caracterizando bioquimicamente estado caquético (tabela 1). A suplementação com óleo de peixe (SWO) manteve a glicemia $(67,42 \pm 2,36 \mathrm{mg} / \mathrm{dl})$, lactatemia $(1,37 \pm 0,02 \mathrm{mmol} / \mathrm{L})$ e triacilglicerolemia $(52,31 \pm 5,86 \mathrm{mg} / \mathrm{dl})$ próximas daquela dos animais sem tumor, mas significativamente diferentes do grupo com tumor sedentário ( $p<0,05$ vs. SW). O exercício (EXW) também aumentou causou manutenção da glicemia $(71,32 \pm 1,97 \mathrm{mg} / \mathrm{dl})$, da lactemia $(1,34 \pm 0,02$ $\mathrm{mmol} / \mathrm{L})$ e da triacilglicerolemia $(67,46 \pm 4,14 \mathrm{mg} / \mathrm{dl})$ ( $p<0,05$ vs SW). A associação de ambas (EXWO) terapias não causou efeito adicional

Tabela 1. Concentração sérica de glicose, lactato e triacilglicerol nos ratos dos grupos sem ou com tumor sedentário (S ou SW), exercitado (EX ou EXW), suplementado com óleo de peixe (SO ou SWO) e associação e exercício e suplementação com óleo de peixe (EXO ou EXWO). Os dados representam a média \pm EPM de 15 animais por grupo.

\begin{tabular}{c|c|c|c}
\hline & $\begin{array}{c}\text { Glicemia } \\
(\mathbf{m g} / \mathbf{d L})\end{array}$ & $\begin{array}{c}\text { Lactato } \\
(\mathbf{m m o l} / \mathbf{L})\end{array}$ & $\begin{array}{c}\text { TAGs } \\
(\mathbf{m g} / \mathbf{d L})\end{array}$ \\
\hline S & $74,98 \pm 1,79$ & $1,34 \pm 0,03$ & $42,73 \pm 7,21$ \\
\hline SO & $82,00 \pm 2,71$ & $1,31 \pm 0,04$ & $48,80 \pm 6,42$ \\
\hline EX & $81,97 \pm 2,25$ & $1,30 \pm 0,04$ & $37,14 \pm 3,06$ \\
\hline EXO & $79,84 \pm 2,86$ & $1,25 \pm 0,04$ & $35,18 \pm 0,71$ \\
\hline SW & $57,70 \pm 0,91^{\mathrm{a}}$ & $1,49 \pm 0,01 \mathrm{a}$ & $183 \pm 21,19 \mathrm{a}$ \\
\hline SWO & $67,42 \pm 2,36^{\mathrm{b}}$ & $1,37 \pm 0,02 \mathrm{~b}$ & $52,31 \pm 5,86 \mathrm{~b}$ \\
\hline EXW & $71,32 \pm 1,97^{\mathrm{b}}$ & $1,34 \pm 0,02^{\mathrm{b}}$ & $67,46 \pm 4,14 \mathrm{~b}$ \\
\hline EXWO & $71,24 \pm 2,46$ & $1,37 \pm 0,02$ & $60,55 \pm 5,26$ \\
\hline
\end{tabular}


$(p>0,05)$ nestes parâmetros, quando comparado ao exercício (EXW) e suplementação isolados (SWO), mas foi diferente do sedentário $(p<0,05)$.

$\mathrm{Na}$ tabela 2 estão os dados referentes ao peso corporal dos animais antes e após implantação do tumor. Nos animais sem tumor o grupo sedentário (S) após duas semanas ganharam em média 5 gramas. A suplementação com óleo peixe (SO) promoveu ganho médio de $13 \mathrm{~g}$ ( $p<0,05$ vs. S). O exercício (EX) causou ganho de $11 \mathrm{~g}(\mathrm{p}<0,05$ vs. S) e a associação de ambas as terapias (EXO), ganho de $13 \mathrm{~g}$ ( $p<0,05$ vs. S). A presença do tumor levou à redução média de $7,5 \mathrm{~g}$ do peso corpóreo ( $p<0,05$ vs. S). A suplementação com óleo de peixe (SWO) impediu a perda de peso (variação positiva de $8,0 \mathrm{~g}, \mathrm{p}>0,05 \mathrm{vs} \mathrm{SO}$ ), sendo superior à do grupo $S W(p<0,05)$. $O$ exercício de salto $(E X W)$ impediu a perda de peso (variação positiva de $3 \mathrm{~g}, \mathrm{p}<0,05 \mathrm{vs}$. SW), contudo o ganho de peso foi inferior quando comparado ao seu controle sem tumor ( $p<0,05$ vs. EX). A associação de ambas as terapias (EXWO) não causou efeito adicional, prevalecendo o efeito do exercício e não o da suplementação (variação positiva de $3 \mathrm{~g}, \mathrm{p}<0,05$ vs. EXO).

Tabela 2. Peso corpóreo antes e após 15 dias da implantação do tumor (g), peso do tumor (g) e variação de peso (g) nos ratos dos grupos sem ou com tumor sedentário (S ou SW), exercitado (EX ou EXW), suplementado com óleo de peixe (SO ou SWO) e associação e exercício e suplementação com óleo de peixe (EXO ou EXWO). Os dados representam a média \pm EPM de 15 animais por grupo

\begin{tabular}{c|c|c|c|c|c}
\hline & $\begin{array}{c}\text { Peso (g) } \\
\text { no dia da } \\
\text { inoculação } \\
\text { do tumor }\end{array}$ & $\begin{array}{c}\text { Peso (g) } \\
\mathbf{1 5} \text { dias após } \\
\text { inoculação } \\
\text { do tumor }\end{array}$ & $\begin{array}{c}\text { Ganho de } \\
\text { peso }(\mathbf{g}) \\
\text { bruto } \\
\mathbf{1 5} \text { dias após } \\
\text { inoculação }\end{array}$ & $\begin{array}{c}\text { Peso (g) } \\
\text { do tumor }\end{array}$ & $\begin{array}{c}\text { Variação } \\
\text { de peso (g) }\end{array}$ \\
\hline S & $396,3 \pm 10,10$ & $401,4 \pm 9,50$ & $5,1 \pm 5,67$ & - & $5,1 \pm 5,67$ \\
\hline SO & $395,5 \pm 9,52$ & $408,5 \pm 11,90$ & $13,0 \pm 6,95$ & - & $13,0 \pm 6,95^{\text {a }}$ \\
\hline EX & $369,0 \pm 8,93$ & $380,3 \pm 11,90$ & $11,3 \pm 6,67$ & - & $11,3 \pm 6,67^{a}$ \\
\hline EXO & $389,7 \pm 8,80$ & $404,9 \pm 7,91$ & $13,7 \pm 5,67$ & - & $13,7 \pm 5,67^{a}$ \\
\hline SW & $383,2 \pm 17,11$ & $400,7 \pm 19,83$ & $17,8 \pm 7,92$ & $25,32 \pm 4,37$ & $-7,52 \pm 2,177^{a}$ \\
\hline SWO & $375,2 \pm 13,67$ & $396,3 \pm 14,06$ & $21,7 \pm 7,49$ & $13,65 \pm 2,92$ & $8,05 \pm 3,19$ \\
\hline EXW & $366,8 \pm 9,66$ & $385,0 \pm 11,75$ & $16,4 \pm 6,83$ & $12,78 \pm 2,25$ & $3,62 \pm 1,43^{b}$ \\
\hline EXWO & $368,2 \pm 9,36$ & $381,2 \pm 11,44$ & $13,0 \pm 6,89$ & $9,69 \pm 1,59$ & $3,31 \pm 1,27^{c}$ \\
\hline
\end{tabular}

${ }^{a p}<0,05$ vs. S. bp $<0,05$ vs. EX. $c p<0,05$ vs. EXO.

Na figura 2 estão apresentados os dados de proliferação de células tumorais cultivadas "ex vivo" durante 24 horas. A suplementação com óleo de peixe (SWO) causou redução significativa ( $p<0,05$ vs. SW) da proliferação de células tumorais. O exercício físico (EXW) reduziu ainda mais significativamente a proliferação de células tumorais quando comparada à dos grupos SW $(p<0,001)$ e SWO $(p<0,05)$. Ao associar óleo de peixe e exercício (EXWO) não observamos efeito aditivo, sendo o resultado similar ao do provocado pelo exercício isoladamente ( $p<0,001$ vs. SW e $p<0,05$ vs. EXW).

$\mathrm{Na}$ figura 3 estão apresentados os dados referentes à lipoperoxidação da massa tumoral. A suplementação com óleo de peixe (SWO) duplicou a lipoperoxidação na massa tumoral $(70,96 \mathrm{nmol} / \mathrm{mg}$ proteína) quando comparada á do grupo sedentário $(p<0,05)$. O exercício físico (EXW) também provocou este mesmo efeito na massa tumoral $(82,40 \mathrm{nmol} / \mathrm{mg}$ proteína) quando comparada à do grupo $\mathrm{SW}(\mathrm{p}<0,05)$. Quando associado o exercício físico e a suplementação com óleo de peixe (EXWO) não foi observado efeito adicional na produção de lipoperóxidos $(85,63 \mathrm{nmol} / \mathrm{mg}$ proteína) quando comparada à do grupo sedentário portador de tumor (SW) $(p<0,05)$.

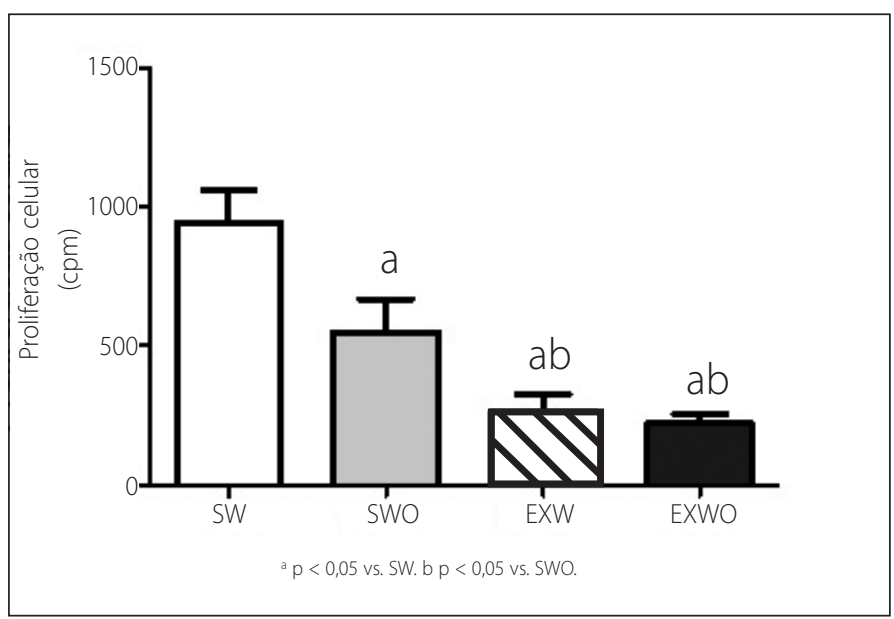

Figura 2. Proliferação das células tumorais "ex vivo" em contagem por minuto (cpm), após 24 horas de cultivo na presença de (14C)-timidina em DNA. As células foram obtidas dos animais Sedentários (SW), Sedentário suplementado com óleo de peixe (SWO), Exercitado (EXW), Exercitado suplementado com óleo de peixe (EXWO). Os dados representam a média \pm EPM de três experimentos em quintuplicata.

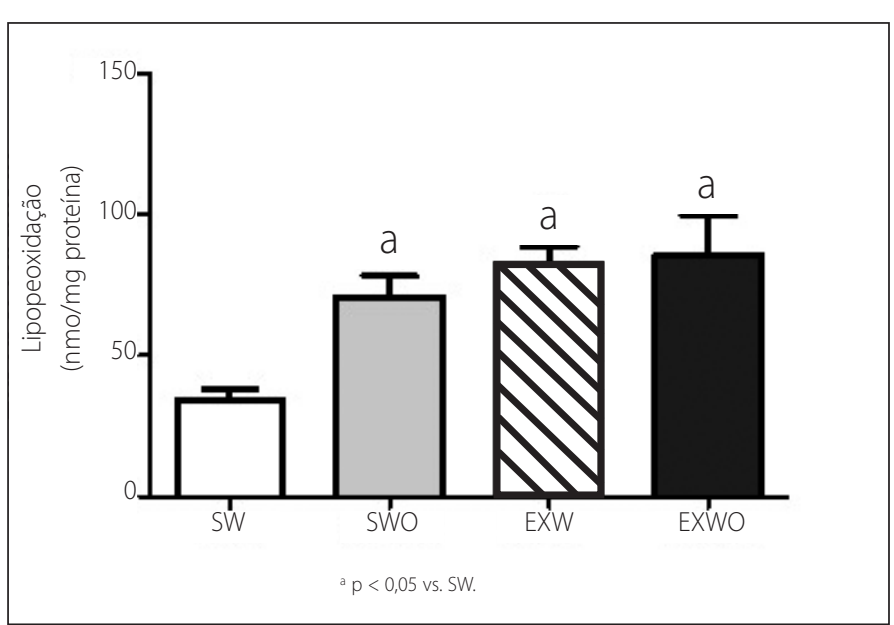

Figura 3. Lipoperoxidação (nmol/mg proteína no tumor) nos tumores dos animais dos grupos Sedentário (SW), Sedentário suplementado com óleo de peixe (SWO), Exercitado (EXW), Exercitado suplementado com óleo de peixe (EXWO). Os dados estão apresentados como média \pm EPM.

Na figura 4 estão os dados referentes à expressão da proteína bcl-2. A suplementação com óleo de peixe (SWO) reduziu significativamente a expressão de $\mathrm{BCl}-2$ em $13 \%$ quando comparada à do grupo SW $(p<0,05)$. O exercício ( $E X W)$ induziu ainda mais esta diminuição em $16 \%$ quando comparada à do grupo SW $(p<0,05)$. A suplementação associada ao exercício físico (EXWO) não teve efeito adicional em relação à diminuição da expressão da Bcl-2 quando comparada à dos grupos SWO e EXW, mas diminui significativamente em 15\% quando comparada à do grupo $S W(p<0,05)$.

\section{DISCUSSÃO}

A dieta com AGPIs n-3 na forma de óleo de peixe vem sendo demonstrada ser capaz de reduzir o crescimento tumoral em modelos ${ }^{17,26}$. Estudos em humanos e em animais têm demonstrado que o exercício também tem efeitos protetores contra malignidades ${ }^{14,31}$, e produzir efeitos benéficos em indivíduos com câncer ${ }^{20}$.

Nesta abordagem experimental, ratos adultos foram suplementados com $1 \mathrm{~g} / \mathrm{kg}$ de peso corporal ${ }^{-1} \cdot$ dia $^{-1}$ de óleo de peixe e submetidos a protocolo de treinamento de saltos durante 8 semanas. Após a implantação do tumor de Walker 256, verificou-se que a suplementação com óleo de peixe rico em AGPIs n-3 e o treinamento de saltos promo- 


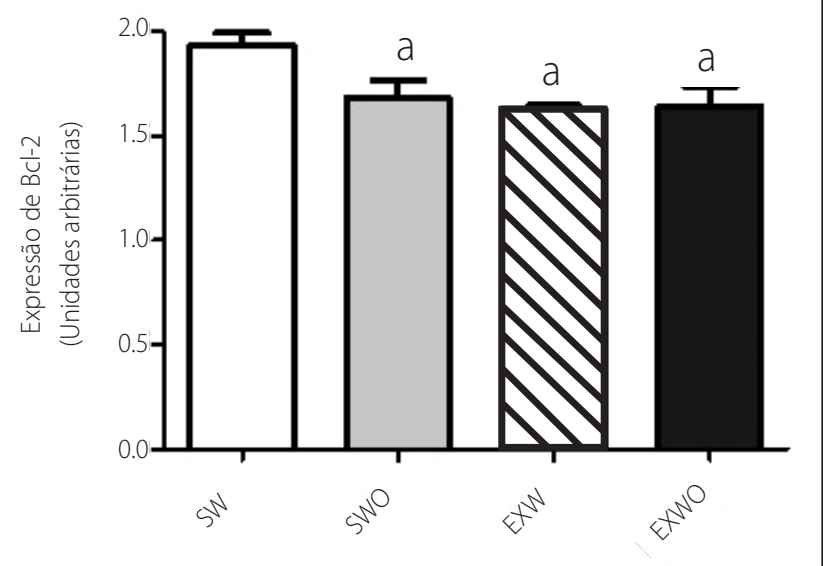

Figura 4. Expressão de $\mathrm{BCl}-2$ no tecido tumoral (unidades arbitrárias) dos animais dos grupos Sedentário (SW), Sedentário suplementado com óleo de peixe (SWO), Exercitado (EXW), e Exercitado suplementado com óleo de peixe (EXWO). Os dados estão apresentados como média \pm EPM de cinco experimentos em duplicata.

veram menor crescimento significativo do tumor quando comparado ao grupo sedentário (SW). A suplementação associada ao treinamento de saltos não apresentou efeito aditivo quanto a este parâmetro.

Além da diminuição do crescimento tumoral observado neste estudo, o exercício físico e a suplementação com óleo de peixe também foram capazes de atenuar algumas mudanças metabólicas decorrentes da instalação da síndrome da caquexia, considerada uma das manifestações mais comuns em doenças malignas avançadas, sendo responsável por 22\% das mortes ${ }^{2}$. O estabelecimento desta é detectado pela presença de hipoglicemia, hiperlactatemia, e hipertriacilglicerolemia, além de redução do conteúdo de glicogênio e perda de peso ${ }^{23}$. Estes sintomas (hipoglicemia, hiperlactatemia, hipertriacilglicerolemia e perda de peso) foram encontrados neste estudo nos ratos com tumor que não foram submetidos a treinamento e/ou suplementação, enquanto que os ratos que realizaram o protocolo de treinamento ou que foram submetidos à suplementação com óleo de peixe não apresentaram estes parâmetros, significando impedimento de instalação do quadro de caquexia.

Estes resultados corroboram resultados obtidos com animais portadores de tumor suplementados com óleo de peixe que apresentaram efetiva redução de parâmetros da caquexia, como menor peso do tumor, menor depleção da massa corpórea, maior glicemia, menor lactatemia, menor triacilglicerolemia, maior produção e menor resistência à insulina, e maior reserva de glicogênio hepático e muscular 8,23.

A manutenção da glicemia nos grupos EXW e EXWO pode ser explicada pelo fato do exercício de força, especificamente, ter a propriedade de aumentar a captação e o transporte de glicose na musculatura esquelética ${ }^{30}$. A menor concentração glicêmica observada no grupo SW em relação à dos demais grupos é explicada pelo fato do tumor de Walker 256 ser o maior consumidor de glicose e produtor de lactato (hiperlaticidemia). Este mecanismo compensatório (gliconeogênese) é necessário para manutenção da glicose plasmática que é parcialmente captada pelo tecido tumoral, bem como outros metabólitos ${ }^{23}$.

Outra alteração metabólica decorrente do intenso quadro catabólico, e aumento da demanda energética que se instala no indivíduo portador de tumor, é o aumento da quebra de gordura que resulta em liberação de glicerol e ácidos graxos. De fato, neste estudo os ratos do grupo SW apresentaram concentração sérica de triacilglicerol significativamente maior que à dos demais grupos (SWO, EXW, EXWO) e também apresentaram maior crescimento tumoral. Estas mudanças ocorrem basicamente devido à inibição da lipase lipoprotéica (LPL) e aumento na atividade da lipase hormônio sensível (HSL). A diminuição da atividade da LPL acarreta em hipertriacilglicerolemia e compromete a absorção de lipídeos pelo tecido adiposo e muscular ${ }^{19}$.

Outro componente importante relacionado à instalação da caquexia é a progressiva perda de peso. A maior perda de peso observada neste estudo foi no grupo sedentário portador de tumor (SW). Suplementos nutricionais que contêm AGPIs n-3 são benéficos para reduzir a perda de peso associada à caquexia/câncer em pacientes com neoplasias em estado avançado. Ensaios clínicos sugerem que AGPIs n-3 podem estabilizar a perda de peso ou levar ao ganho de peso em pacientes com câncer avançado com caquexia ${ }^{16,29}$. Esta perda de peso corporal em indivíduos caquéticos está associada à presença de fator indutor de proteólise (PIF) secretado pelo tumor ${ }^{27}$. A manutenção do peso corporal encontrado tanto nos animais suplementados, como nos animais exercitados, corrobora um crescente corpo de evidências indicando os benefícios potenciais do exercício físico para a melhoria da qualidade de vida de pacientes com câncer ${ }^{6,22}$. O potencial da aplicação do exercício em várias condições parece estar correlacionado com a promoção de adaptações em todos os sistemas do organismo.

Vários mecanismos têm sido propostos para explicar as ações dos AGPIs n-3 na carcinogênese. Dentre estes, está a habilidade de AGPIs n-3 em induzir apoptose nas células tumorais, a qual tem sido atribuída à suscetibilidade aumentada destas células à peroxidação lípidica 24,25. A suplementação com óleo de peixe (SWO) neste estudo foi capaz de induzir a produção de maiores quantidades de lipoperóxidos quando comparada à do grupo sedentário portador de tumor (SW). Este resultado corrobora com o estudo de MUND et al., ${ }^{18}$ no qual tumores obtidos de ratos portadores do tumor de Walker 256 suplementados com óleo de peixe, rico em AGPIs n-3, apresentaram maior peroxidação lipídica do que ratos não suplementados. A relação do câncer com a taxa de peroxidação lipídica é explicada pelo fato de que as membranas das células e organelas contêm grandes quantidades de ácidos graxos poli-insaturados e a fluidez da membrana relaciona-se à presença destas cadeias insaturadas de fosfolipídios e do colesterol. Desta forma, danos a esta camada lipídica tendem a diminuir a fluidez da membrana. Embora todos os componentes celulares sejam suscetíveis à ação de espécies reativas de oxigênio, a membrana é uma das mais atingidas em decorrência da peroxidação lipídica, a qual acarreta alterações na estrutura e na permeabilidade das membranas celulares, e consequente perda de seletividade na troca iônica e liberação do conteúdo de organelas com formação de produtos citotóxicos (como o malonaldeído), culminando com a morte celular?.

Estudos tem mostrado que o exercício físico é capaz de induzir e aumentar a peroxidação lipídica ${ }^{9}$ e a produção de radicais livres após a atividade física em modelos animais e humanos ${ }^{4,12}$. No metabolismo oxidativo, grande parte do oxigênio consumido é ligado ao hidrogênio durante o processo de fosforilação oxidativa, gerando água. No entanto, aproximadamente 4-5\% do oxigênio consumido durante a respiração não é completamente reduzido à água, formando radicais livres. Durante o exercício físico o consumo de oxigênio aumenta e em paralelo aumenta também a produção de radicais livres e a peroxidação lipídi$c a^{4}$. A produção de radicais livres e peroxidação lipídica causada pelo exercício físico pode ser um importante mecanismo contra o câncer ${ }^{9}$.

Outro resultado importante nesta investigação refere-se à redução significativa da proliferação de células tumorais no grupo exercitado (EXW) e exercitado suplementado com óleo de peixe (EXWO). Estudos tem mostrado a capacidade do exercício físico em reduzir a proliferação celular juntamente com indução do apoptose em células neoplásicas ${ }^{10,14}$. Isto pode ser explicado pelo fato de o exercício físico contribuir para diminuição das concentrações séricas de IGF-1 (fator de crescimento parecido com a insulina) e aumentar os da proteína ligadora de IGF-1 (IGFBP-1), ${ }^{28}$ diminuindo ainda mais a concentração 
de IGF-1 livre e, consequentementeo, reduzindo o estímulo de crescimento na célula tumoral. A mudança na concentração sérica desta proteína pode aumentar o conteúdo da proteína p53 no tumor, que tem função de proteger o genoma de mutações e alterações genéticas. Quando ocorrem erros no DNA a p53 tem a função de ativar genes ou fatores que causam a parada do ciclo celular, ou que façam a célula entrar em apoptose à partir da transcrição de genes de proteínas pró-apoptóticas. O aumento na concentração de p53 no tecido tumoral leva a aumento na relação $\mathrm{Bax} / \mathrm{BCl}-2^{10}$, o que propicia a entrada da célula no processo de morte programada, culminando com a ativação da cascata de caspases. Este poderia ser um possível mecanismo pelo qual os grupos exercitados mostraram menor capacidade proliferativa de células tumorais.

Resistência a apoptose é uma das principais características adquiridas pelas células tumorais ${ }^{21}$. Um dos fatores determinantes para a célula entrar ou não neste processo de morte programada é a relação entre as concentrações das proteínas pró (Bax) e anti-apoptóticas (Bcl2). Sendo assim, células que têm superexpressão de Bcl-2 poderiam escapar da apoptose pelo fato de estarem inibindo a ativação de proteínas pró-apoptóticas.

Neste estudo observou-se que tanto o exercício físico (EXW) bem como a associação deste com a suplementação com óleo de peixe (EXWO) foram capazes de diminuir a expressão de Bcl-2 quando comparada à do grupo SW (FIGURA 4), favorecendo o balanço pró-apoptótico no ambiente tumoral. Tem sido demonstrado que suplementação com óleo de peixe aumenta a apoptose em modelos animais com carcinogênese coloretal ${ }^{15}$. A suplementação com óleo de peixe (SWO) também foi hábil em diminuir Bcl-2, sugerindo que a down-regulation de $\mathrm{BCl}-2$ pode ser um dos mecanismos pelos quais o óleo de peixe sensibiliza a apoptose em células cancerosas ${ }^{15}$. A expressão aumentada de $\mathrm{Bcl}$-2 e de seus homólogos anti-apoptóticos não apenas promove proteção contra apoptose, como também aumenta o tempo de vida da célula ${ }^{13}$. A manutenção dos mecanismos anti-apoptóticos estão relacionados com a sobrevivência celular, sendo estes indesejáveis em células que sofreram mutação.

\section{CONCLUSÕES}

Os resultados desta investigação sugerem que a suplementação com óleo de peixe e o protocolo de treinamento de força foram eficazes na redução do crescimento do tumor, na redução da proliferação das células tumorais e expressão de Bcl-2, e na atenuação da instalação da caquexia. A associação da suplementação com óleo de peixe ao treinamento de força não causou efeito aditivo no balanço pró-apoptótico em relação àquele já promovido por ambos isoladamente, o que pode indicar uma via comum de ação.

Estes resultados corroboram a hipótese de que o exercício físico e a suplementação com óleo de peixe possuem funções importantes no auxílio do tratamento de portadores de tumor e que ambos os tratamentos compartilham os mesmos mecanismos celulares de inibição do crescimento tumoral.

Todos os autores declararam não haver qualquer potencial conflito de interesses referente a este artigo.

\section{REFERÊNCIAS}

1. Al-Majid S, McCarthy DO. Resistance Training attenuates wasting of the extensor digitorum longus muscle in mice bearing the Colon-26 Adenocarcinoma. Biolog Res Nurs. 2001;3:155-66.

2. Argilés JM, Busquets S, LopesSoriano FJ. The pivotal role of cytokines in muscle wasting during cancer. Int J Biochem Cell Biol. 2005;37:2036-46.

3. Bradford MM. A rapid and sensitive method for the quantification of microgram quantities of protein utilizing the principle of protein-dye binding. Anal Biochem. 1976;72:248-54.

4. Clarkson PM, Thompson HS. Antioxidants: what role do they play in physical activity and health? Am J Clin Nutr. 2000;72:637S-46S.

5. Courneya K, Friedenreich CM. Relationship between exercise pattern across the cancer experience and current quality of life in colorectal cancer survivors. J Altern Complement Med. 1997;3:215-26.

6. Courneya KS, Segal RJ, Reid RD, Jones LW, Malone SC, Venner PM, Parliament MB, Scott CG, Quinney HA, Wells GA. Three independent factors predicted adherence in a randomized controlled trial of resistance exercise training among prostate cancer survivors. J Clin Epidemiol. 2004;57(6):571-9.

7. Ferreira ALA, Matsubara LS. Radicais livres: conceitos, doenças relacionadas, sistema de defesa e estresse oxidativo. Rev Assoc Med Bras. 1997; 43(1):61-8.

8. Folador A, Hirabara SM, Bonatto SJR, Aikawa J, Yamazaki RK, Curi R, Fernandes LC. Effect of fish oil supplementation for 2 generations on changes in macrophage function induced by Walker 256 cancer cachexia in rats. Int. J. Cancer. 2006;120:344-50.

9. Gago-Dominguez M, Castelao J, Pike MC, Sevanian A, Haile RW. Role of lipid peroxidation in the epidemiology and prevention of breast cancer. Cancer Epidemiol Biomarkers Prev. 2005;14:2829-39.

10. Jiang $X$, Wang $X$. Cytochrome c promotes caspase- 9 activation by inducing nucleotide binding to Apaf-1. J. Biol. Chem. 2000;275:31199-203.

11. Jiang Y, Woollard ACS, Wolff SP. Lipid Hydroperoxide Measurement by Oxidation of Fe+2 in the Presence of Xilenol Orange. Comparison with the TBA Assay and an lodometric Method. Lipids.1991;26:853-6.

12. Jill. Exercise, oxidative stress, and antioxidants. Am J Sports Med. 1996;24: S20-4.

13. Kim H, Shah MR, Tu HC, Jeffers JR, Zambetti GP, Hsieh JD, Cheng EHY. Hierarchical regulation of mitochondrion-dependent apoptosis by BCL-2 subfamilies. Nature Cell Biology. 2006;8:1348-58.

14. Leung PS, Aronson WJ, Ngo TH, Golding LA, Barnard RJ. Exercise alters the IGF axis in vivo and increases p53 protein in prostate tumor cells in vitro. J Appl Physiol. 2004;96:450-4.

15. Manna S, Chakraborty T, Ghosh B, Chatterjee M, Panda A, Srivastava S, Rana A, Chatterjee M. Dietary fish oil associated with increased apoptosis and modulated expression of Bax and $\mathrm{BCl}-2$ during 7,12-dimethylbenz(a)anthracene-induced mammary carcinogenesis in rats. Prostaglandins Leukot Essent Fatty Acids. 2008;79(1-2):5-14.

16. Mantovani G, Maccio A, Madeddu C, Gramignano G, Lusso MR, Serpe R, Massa E, Astara G, Deiana L. A phase II study with antioxidants, both in the diet and supplemented, pharmaconutritional support, progestagen, and anti-cyclooxygenase-2 showing efficacy and safety in patients with cancer-related anorexia/cachexia and oxidative stress. Cancer Epidemiol Biomarkers Prev. 2006; 15:1030-4.

17. Minuzzi LG. Estudo da associação do exercício físico e da suplementação com óleo de peixe sobre crescimento tumoral, caquexia e imunidade em ratos com tumor de Walker 256. Dissertação de Mestrado, UFPR, 2006.

18. Mund RC, Pizzato N, Bonatto S, Nunes E, Vicenzi T, Tanhoffer T, Oliveira HP, Curi R, Calder PC, Fernandes LC. Decreased tumor growth in Walker 256 tumor-bearing rats chronically supplemented with fish oi involves COX-2 and PGE2 reduction associated with apoptosis and increased peroxidation. Prostaglandins Leukot Essent Fatty Acids. 2007;76 (2):113-20.

19. Noguchi Y, Makino T, Yoshikawa T, Nomura K, Fukuzawa K, Matsumoto A, Yamada T. The possible role of TNF-alpha and IL-2 in inducing tumor associated metabolic alterations. Surg. Today.1996;26:36-41.

20. Nunes EA, Navarro F, Bacurau RFP, Pontes Junior FL, Fernandes LC. Mecanismos potenciais pelos quais o treinamento de força pode afetar a caquexia em pacientes com câncer. Revista Brasileira de Prescrição e Fisiologia do Esforço. 2007;1(1):1-17.

21. Perkins ND. NF-KB: tumor promoter or suppressor? Trends Cell Biol. 2004;14:64-9.

22. Pinto BM, Maruyama NC. Exercise in the rehabilitation of breast cancer survivors. Psychooncology. 1999;8(3):191-206.

23. Pinto JA, Folador A, Bonato SJ, Aikawa J, Yamazaki RK, Pizato N, Facin M, Grohs H, De Oliveira HH, Naliwaiko K, Ferraz AC, Nishiyama, A, Fernandez R, Curi R, Fernandes LC. Fish oil supplementation in F1 generation associated with naproxen, clenbuterol, and insulin administration reduce tumor growth and cachexia in Walker 256 tumorbearing rats. J Nutr Biochem. 2004;15(6): 358-65.

24. Spiteller G. Are lipid peroxidation processes induced by changes in the cell wall structure and how are these processes connected with diseases? Med Hypotheses. 2003;60(1):69-83.

25. Stoll BA. N-3 fatty acids and lipid peroxidation in breast cancer inhibition. Br J Nutr. 2002;87193-8.

26. Tapiero H, Nguyen BA, Couvreur P, Tew KD. Polyunsaturated fatty acids and eicosanoids in human health and pathologies. Biomed Pharmacother. 2002;56: 215-22.

27. Tisdale MJ. Protein loss in cancer cachexia. Science. 2000;289:2293-5.

28. Tymchuk CN, Tessler SB, Aronson WJ, Barnard RJ. Effects of diet and exercise on insulin, sex hormone-binding globulin, and rostatespecific antigen. Nutr. Cancer. 1998;31:127-31.

29. Wigmore SJ, Barber MD, Ross JA, Tisdale MJ, Fearon KC. Effect of oral eicosapentaenoic acid on weight loss in patients with pancreatic cancer. Nutr Cancer. 2000;36:177-84

30. Yaspelkis BB, Singh MK, Trevino B, Krisan AD, Collins DE. Resistance training increases glucose uptake and transport in rat skeletal muscle. Acta Physiol Scand. 2002;175(4):315-23.

31. Zielinski MR, Muenchow M, Wallig MA, Horn PL, Woods JA. Exercise delays allogeneic tumor growth and reduces intratumoral inflammation and vascularization. J Appl Physiol. 2004;96:2249-56. 